\title{
PERAN KOMITE SEKOLAH DALAM MENINGKATKAN MUTU LAYANAN PENDIDIKAN DI SEKOLAH DASAR NEGERI SE-KECAMATAN CAKRANEGARA
}

\author{
IGusti Ayu Aristianti Pratiwi, Hamidsyukrie ZM, Muntari \\ Program Pascasarjana Universitas Mataram \\ s2apunram.aristianti@gmail.com, hamidsyukrie@yahoo.com,
}

\begin{abstract}
ABSTRAK: Tujuan penelitian ini adalah untuk mendapatkan gambaran konkrit mengenai peran komite sekolah dalam meningkatkan mutu layanan pendidikan di SDN se-Kecamatan Cakranegara, baik sebagai badan pemberi pertimbangan, badan pendukung, badan pengontrol, dan badan penghubung. Data dan informasi dikumpulkan dengan metode observasi, wawancara dan dokumentasi. Hasil penelitian menyatakan bahwa komite sekolah sudah melaksanakan perannya dengan baik sebagai badan pemberi pertimbangan (advisory agency) dan sebagai badan pendukung (supporting agency). Peran sebagai badan penghubung (mediator agency) adalah peran yang paling optimal dilaksanakan oleh komite sekolah. Komite sekolah sangat terbuka, cepat tangggap, dan komunikatif dalam menerima masukan dan kritikan dari seluruh stakeholder. Namun begitu, peran sebagai badan pengawas (controlling agency) belum efektif untuk dilaksanakan oleh komite sekolah. Hal ini terjadi karena komite sekolah hanya melakukan pengawasan melalui laporan yang dibuat oleh sekolah, kunjungan pengawasan jarang dilakukan karena keterbatasan waktu dan kesibukan pengurus. Untuk mengatasi hal ini, perlu peningkatan komunikasi, kerjasama, dan kesadaran pada seluruh stakeholder pendidikan agar menjalankan perannya dengan penuh tanggung jawab. Mengenai mutu layanan pendidikan, jika ditinjau dari indikator SPM, maka capaian SPM di SDN A dan SDN B adalah sebesar 79\% dan SDN C sebesar 76\%. Agar dapat mengoptimalkan capaian, maka sekolah perlu meningkatkan partisipasi masyarakat dalam pendidikan.
\end{abstract}

Kata kunci : peran komite sekolah dan mutu layanan pendidikan

ABSTRACT:The purpose of this study was to acquire a concrete picture of the school committees role in improving the quality of education services in the Elementary School throughout the Cakranegara district, either as advisory agency, supporting agency, controlling agency, and mediator agency. The data and information of this research were collected by observation, interview and documentation. The result of this study found that the school committee has been performing its role quite good as advisory agency, supporting agency, controlling agency, and mediator agency. Role as mediator agency is the most optimal role carried out by the school committee. The school committee was very open, fast response, and communicative in receiving feedback and criticism from all stakeholders. However, the role as controlling agency has not been effective to be implemented by the school committee. This could happen because the school committee supervise through reports prepared by the school, committee visitation was rarely done because of time constraints and other business. To overcome this problem, it is necessary to increase communication, collaboration, and awareness of all stakeholders in education in order to carry out its role with full responsibility. Regarding the quality of educational services, using SPM quality indicator, the SPM quality in Elementary School A and B is 79\% and Elementary School C is 76\%. In order to optimize the quality of the services, the elementary school needs to increase the participation of society in education.

Keywords: school committee and the quality of educational services 


\section{PENDAHULUAN}

Mutu layanan pendidikan di Indonesia masih rendah. Dari beberapa forum dan organisasi internasional, seperti UNESCO tahun 2012 menyatakan bahwa dari 120 negara di dunia, pendidikan di Indonesia menduduki urutan ke-64. Menurut PERC kualitas pendidikan di Indonesia menempati urutan ke -12 dari 12 negara di ASIA.

Data diatas menunjukkan bahwa mutu pendidikan di Indonesia masih sangat rendah. Untuk mengatasi masalah itu, pemerintah menetapkan sisdiknas melalui pengesahan UU No.20 Tahun 2003. Pemerintah yakin dan percaya mutu pendidikan dapat ditingkatkan, jika penyelenggaraan pendidikan sesuai dengan standar pelayanan minimal dan ada partisipasi aktif masyarakat dalam dunia pendidikan.

Implikasi dari dikeluarkannya sisdiknas adalah penerapan MBS ( Manajemen Berbasis Sekolah). MBS memberikan keleluasaan bagi sekolah untuk menggali, mengolah, mengembangkan, memanfaatkan, dan mengatur seluruh potensi (sumber daya manusia dan sumber daya pendidikan) yang ada di sekolah guna itu, guna mencapai tujuan pendidikan nasional.

Prinsip penerapan MBS adalah keterlibatan masyarakat dalam pendidikan. Untuk mewadahi aspirasi dan partisipasi masyarakat dalam pendidikan maka dibentuklah dewan pendidikan dan komite sekolah. Dewan pendidikan menaungi pendidikan tingkat kota/kecamatan, sedangkan komite sekolah bernaung pada setiap satuan pendidikan.

Hasil observasi awal peneliti di lapagan menyatakan bahwa (1) komite sekolah tidak aktif dalam menjalankan perannya, baik sebagai badan pemberi pertimbangan, dukungan, pengawasan, maupun sebagai badan penghubung; (2) tingkat SDM komite sekolah yang masih rendah, menyebabkan komite sekolah merasa rendah diri dalam menajalankan perannya; (3) proses pembentukan pengurus komite sekolah belum sesuai dengan pedoman pementukan pengurus komite sekolah;(4) AD/ART disusun sendiri oleh kepala sekolah tanpa campur tangan komite sekolah; (5) komite sekolah hanya berperan sebagai legalitas kebijakan/program sekolah; (6) adanya anggapan masyarakat, bahwa komite sekolah sama dengan BP3, hanya mendukung pendidikan melalui pengumpulan dana.

Masalah diatas adalah satu kesatuan, untuk mengatasi masalah diatas diperlukan waktu dan proses yang bertahap. Perlu kematang internal dalam penyelenggaraan pendidikan, perubahan tatanan dalam pola berpikir, mengedepankan prinsip demokrasi, ketrbukaan, dan akuntabilitas, disamping menjunjung tinggi prinsip lainnya yang tentu harus dilaksanakan secara komprehensif.

Penelitian ini berfokus pada empat peran penting komite sekolah yang tercantum dalam Kepmendiknas No.044/U/2002 tanggal 2 April 2002, yaitu sebagai badan pemberi pertimbangan (advisory agency), badan pendukung (supporting agency), badan pengontrol (Controlling agency), dan badan penguhubung (mediating agency). Menurut Raharjo (Depdiknas, 2002:03), mutu pendidikan Indonesia masih belum meningkat secara signifikan. Hal ini bertentangan dengan pendapat Sartika (2002;93) yang menyatakan bahwa jaminan kualitas pada hakekatnya berhubungan dengan bagaimana menentukkan dan 
menyampaikan apa yang dipromosikan kepada konsumen, lebih dari itu kita telah memulai untuk memperbaiki proses penentuan apa yang pelanggan inginkan untuk merancang kualitas produksi dan prosesnya menggunakan metode seperti penyebaran fungsi kualitas. Namun jika kualitas ditentukan sebagai kepuasan pelanggan produksi mengikuti kualitas yang diharapkan melalui proses yang melayani pelanggan.

\section{METODE PENELITIAN}

Penelitian ini menggunakan metode penelitian kualitatif deskriptif. Penelitian kualitatif deskriptif merupakan metode yang menggambarkan permasalahan atau kasus yang dikemukakan berdasarkan fakta yang ada dengan berpijak pada fakta yang bersifat khusus kemudian diteliti untuk dipecahkan permasalahannya, ditarik kesimpulan dari masalah tersebut. Oleh karena itu,peneliti akan menggambarkan peran komite sekolah dalam meningkatkan mutu layanan pendidikan di SD Negeri se-Kecamatan Cakranegara.

Penelitian ini mengambil latar penelitian di tiga SDN yang ada di Kecamatan Cakranegara dengan alasan : (1) SDN 3 Cakranegara adalah Sekolah Dasar Negeri yang berhasil menduduki urutan 3 besar dalam hasil Ujian Nasional selama 5 Tahun berturut-turut; (2) SDN 20 Cakranegara adalah sekolah dasar negeri tempat peneliti mengabdikan diri sebagai guru. Selama 5 Tahun berturut-turut nilai rata-rata ujian nasional SDN 20 Cakranegara berada di peringkat 30 besar. Selain itu juga SDN 20 sangat unggul dalam prestasi non akademik, khususnya bidang kesenian; (3)
SDN 41 Cakranegara dipilih sebagai wakil dari SDN yang minim prestasi. SD ini pernah ditutup oleh pemerintah karena kekurangan murid. Masyarakat sekitar enggan menyekolahkan anak-anak mereka di SD ini karena kepala sekolahnya terlibat kasus korupsi. Selain itu, guru yang mengajar di SD ini adalah guru-guru senior yang hampir memasuki masa purna tugas.

Sumber data primer dalam penelitian ini diperoleh melalui wawancara yang peneliti dengan guru, kepala sekolah, dan komite sekolah. Selain itu, peneliti juga melakukan observasi lapangan dan mengumpulkan data dalam bentuk catatan tentang peran serta komite sekolah dalam meningkatkan mutu layanan pendidikan. Sumber data sekunder diperoleh dari hasil observasi, studi pustaka dan dokumentasi.

Subjek Penelitian atau Informan Penelitian diambil menggunakan teknik purposive random sampling, Subjek penelitian secara keseluruhan berjumlah 9 orang, terdiri dari 3 orang guru, 3 orang kepala sekolah, dan 3 orang pengurus komite sekolah.

Instrumen penelitian menggunakan instrumen observasi, instrumen wawancara, dan instrumen analisis dokumentasi.

Teknik analisis data yang digunakan dalam penelitian ini adalah menggunakan langkah - langkah seperti yang dikemukakan oleh Bungin (2003:70) yaitu Pengumpulan Data (Data Collecting); (2) Reduksi Data (Data Reduction); (3) Penyajian Data (Display Data); (4) Verifikasi dan penegasan kesimpulan (Conclution Drawing and Verification).

Dalam penelitian kualitatif, dibutuhkan pemeriksaan keabsahan data. Menurut Lincon 
dan Guba (dalam Riyanto,2007) keabsahan data tersebut mencakup uji kredibilitas, transferbilitas, dependabilitas dan konfirmabilitas.

\section{HASIL DAN PEMBAHASAN}

\section{Peran Komite Sekolah dalam Meningkatkan Mutu Layanan Pendidikan}

1. Peran komite sekolah sebagai badan pertimbangan (advisory agency) dalam peningkatan mutu layanan pendidikan

Hasil penelitian menyatakan bahwa komite sekolah di SDN se-Kecamatan Cakranegara sudah melaksanakan perannya dengan baik sebagai badan pertimbangan. Namun demikian, komite sekolah masih perlu meningkatkan keterlibatannya dalam melakukan pendataan mengenai kondisi sosial ekonomi keluarga peserta didik melalui analisis mendalam mengenai kekuatan, kelemahan, peluang, dan ancaman, sehingga komite sekolah dan sekolah bisa mendapatkan informasi yang lebih akurat mengenai potensi sumber dana dan sumber daya pendidikan. Data yang terkumpul baik lisan maupun tulisan dapat dijadikan bahan masukan dan saran dalam menyusun program, kebijakan dan kegiatan sekolah. Hal ini sejalan dengan peran komite sekolah sebagai badan pemberi pertimbangan (advisory agency) dalam penentuan dan pelaksanaan kebijakan pendidikan di satuan pendidikan. indikator kinerja komite sekolah sebagai badan pertimbangan adalah memberikan pertimbangan dan masukan dalam menyusun visi, misi, tujuan, kebijakan, program, penyusunan RKAS, pelaksanaan proses dan pengelolaan pembelajaran dan pendidikan, memberikan pertimbangan mengenai kodisi ketenaga pendidikan serta ketersediaan sarana dan prasarana pendidikan di sekolah.(Kepmendiknas No. 044/U/2002)

2. Peran komite sekolah sebagai badan pendukung (supporting agency) dalam peningkatan mutu layanan pendidikan

Hasil penelitian menyatakan bahwa komite sekolah di SDN se-Kecamatan Cakranegara sudah menjalankan perannya dengan baik sebagai badan pendukung (supporting agency). Hal ini dibuktikan dengan keterlibatan aktif komite sekolah dalam menghimpun bantuan, sumbangan, serta kerelaannya untuk bekerjasama dalam setiap kegiatan yang diadakan di sekolah. Namun, dalam rangka meningkatkan mutu layanan pendidikan, komite sekolah perlu lebih melibatkan dunia insdutri dan usaha dalam pengumpulan sumber daya (tenaga, ide, maupun dana).

Keefektifan peran komite sekolah sebagai badan pendukung ini sejalan dengan pendapat Sartika (2002) bahwa proses pembelajaran dapat berjalan dengan efektif dan bermakna jika dalam pelaksanaannya ditunjang oleh sumber daya (sumber daya manusia, sarana, dan prasarana). Kesediaan komite sekolah untuk mendukung peningkatan mutu layanan pendidikan sudah sesuai dengan amanat dalam Undang-undang Nomor 20 Tahun 2003 tentang Sistem Pendidikan Nasional Pasal 56. Dalam pasal itu tercantum bahwa komite sekolah dan madrasah diberikan peran untuk meningkatkan kualitas pelayanan 
pendidikan melalui: (1) nasihat; (2) pengarahan; (3) bantuan personalia, material, dan fasilitas; maupun (4) pengawasan pendidikan. Hal ini juga sejalan dengan prinsip pelaksanaan MBS yaitu pelibatan masyarakat dalam pendidikan, dengan mengajak bekerjasama (togetherness) seluruh stakeholder dan memanfaatkan potensi yang ada, sehingga semua potensi dapat dikembangkan secara optimal sesuai dengan kemampuannya.

3. Peran komite sekolah sebagai badan pengawas (controlling agency) dalam peningkatan mutu layanan pendidikan

Komite sekolah sebagai badan pengawas di SDN se-Kecamatan Cakranegara secara umum belum berjalan dengan baik. Hal ini disebabkan oleh keseragaman persepsi mengenai peran komite sekolah. Komite sekolah beranggapan bahwa tugas dan wewenangnya hanya membantu kelancaran pendidikan, tanpa mencampuri urusan teknis pengajaran, termasuk wewenang kepala sekolah, guru, maupun pembina pendidikan. Selain itu pengawasan yang dilakukan hanya terfokus pada penggunaan sumber daya pendidikan, sedangkan pengawasan terhadap input dan output pendidikan, serta keterlaksanaan seluruh program yang telah disusun bersama dengan pihak sekolah hanya dilakukan melalui laporan yang dikirimkan oleh pihak sekolah. Pengawasan yang dilakukan oleh komite sekolah hendaknya mencakup semua komponen input, proses, output dan outcome dalam pendidikan, serta dilakukan secara berkesinambungan.
Komite sekolah hendaknya membuat laporan pengawasan, baik secara lisan maupun tulisan mengenai hasil dan temuannya.

Dalam rangka mencapai transaparansi dan akuntabilitas pendidikan, maka komite sekolah berperan dalam mengontrol atau mengawasi kebijakan program, penyelenggaraan dan keluaran pendidikan di setiap satuan pendidikan yang dinaunginya, maka peran komite sekolah sebagai badan pengawas (controlling agency) harus lebih ditingkatkan (Sujanto,2007:63).

4. Peran komite sekolah sebagai badan mediator (mediator agency) dalam peningkatan mutu layanan pendidikan

Berdasarkan hasil penelitian mengenai peran komite sekolah dalam meningkatkan mutu layanan pendidikan, bahwa dari keempat peran komite sekolah yang tertuang dalam UU No.044/U/2002, maka peran sebagai pemberi pertimbangan dan pendukung dalam perencanaan dan pelaksanaan pendidikan sudah mampu dilaksanakan dengan baik oleh komite sekolah di SDN se-Kecamatan Cakranegara. Walaupun peran sebagai badan pengontrol (controlling agency) belum optimal untuk dijalankan, hal ini diakibatkan oleh keberagaman pendapat mengenai peran dan fungsi komite sekolah. Tetapi perannya sebagai penghubung (mediator agency) adalah peran yang paling optimal dilaksanakan oleh komite sekolah. Hal ini dikarenakan oleh sikap komite sekolah yang selalu terbuka dan demokratis dalam menampung aspirasi masyarakat. Dua 
peran lainnya, yaitu sebagai badan pemberi pertimbangan (advisory agency) dan sebagai pendukung (supporting agency).

Capaian SPM dalam rangka meningkatkan mutu layanan pendidikan

Capaian SPM di SDN A dan B adalah sebesar 79\% dan SDN C sebesar 76\%. Hampir semua indikator SPM sudah dipenuhi oleh semua SDN se-Kecamatan Cakranegara. Beberapa indikator SPM yang belum terpenuhi antara lain berkaitan dengan jumlah tenaga pendidik, belum tersedianya laboratorium, kurangnya jumlah buku teks. Untuk mengatasi kekurangan guru, selain memanfaatkan jasa guru honorer, komite sekolah sebagai badan penghubung (mediator agency) juga sudah melaporkan ke dinas pendidikan Kota Mataram, namun hingga saat ini belum mendapatkan tanggapan positif, hal ini dikarenakan jumlah perekrutan guru baru lebih sedikit dibandingkan dengan jumlah guru yang memasuki masa pensiun. Semua SDN belum memiliki laboratorium, karena DAK yang diterima sekolah baru mampu digunakan untuk merenovasi kelas. Jumlah buku teks yang kurang dikarenakan banyak hal, antara lain karena buku paket kurang dipelihara dengan baik serta penerapan kurikulum yang masih simpang siur. Untuk kegiatan ibadah, masing-masing SDN sudah menyediakan tempat ibadah melalui swadaya masyarakat.

\section{Simpulan}

Komite sekolah di SDN seKecamatan Cakranegara sudah menjalankan perannya sebagai badan pertimbangan (advisory agency), badan pendukung (supportinkg agency), dan badan penghubung (mediating agency) dengan baik. Namun, komite sekolah di SDN se-Kecamatan Cakranegara belum optimal dalam menjalankan perannya sebagai badan pengawas (controlling agency).

Berdasarkan indeks pencapaian Standar Pelayanan Minimal (SPM), maka hasil capaian SPM untuk SDN A dan SDN B adalah 79\%, sedangkan SDN C sebesar 76\%. Agar capaian SPM lebih optimal, dibutuhkan kerjasama dan kesadaran yang baik pada seluruh stakeholder pendidikan.

\section{Implikasi Hasil Penelitian}

1. Badan pertimbangan, komite sekolah dapat meningkatkan perannya dalam (a) mendata kondisi sosial, ekonomi, budaya peserta didik serta sumber daya pendidikan di sekolah; (b) aktif dalam memberikan masukan dan peryimbangan kepada sekolah dalam membuat program, dan kebijakan sekolah; (c) melakukan analisis terhadap hasil pendataan sebagai bahan dalam memberikan pertimbangan, masukan, dan rekomendasi kepada sekolah; (d) penyampaian masukan, pertimbangan, dan rekomendasi secara lisan dan tertulis kepada sekolah dengan tembusan dinas pendidikan; (e) memberikan pertimbangan kepada sekolah dalam pengembangan kurikulum dan muatan local serta proses pembelajaran; (f) melakukan verifikasi dan pengesahan RKAS yang diajukan oleh sekolah.

2. Sebagai badan pendukung, komite sekolah dapat lebih meningkatkan perannya dalam pemberian dukungan kepada sekolah dalam pelaksaan kegiatan 
ekstrakurikuler serta menjalin kerjasama dengan dunia industri dalam rangka meningkatkan mutu layanan pendidikan di sekolah.

3. Sebagai badan pengontrol komite sekolah dapat lebih berperan dalam: (a) meminta penjabaran kepada sekolah tentang hasil belajar siswa; (b) memperoleh masukan, saran, dan ide kreatif dari masyarakat. (c) menyampaikan laporan kepada sekolah secara tertulis tentang hasil pengamatan komite sekolah terhadap sekolah.

4. Sebagai badan penghubung komite sekolah dapat lebih berperan dalam: (a) membantu sekolah dalam menciptakan hubungan dan kerjasama antara sekolah dengan orang tua/wali murid dan masyarakat; (b) mengadakan rapat atau pertemuan dengan kepala sekolah dan dewan guru; (c) bekerja sama dengan sekolah dalam kegiatan penelusuran alumni. (d) membina hubungan dan kerjasama dengan stakeholder pendidikan dengan dunia usaha/industri; mengadakan kegiatan inovatif untuk meningkatkan kesadaran dan kemitraan masyarakat; (g) mengadakan rapat atau pertemuan dengan orang tua/wali murid dan anggota masyarakat.

5. Mutu layanan pendidikan adalah adanya jaminan proses atau layanan penyelenggaraan pendidikan di sekolah dasar negeri agar sesuai bahkan melebihi standar yang telah ditetapkan dan mampu memenuhi keinginan para pelanggannya ( peserta didik dan masyarakat). Mutu layanan pendidikan dapat ditingkatkan jika (a) fungsi dan tujuan pendidikan melekat pada pelaksana dan pelaksanaan pendidikan, pendidikan harus terselenggara dengan demokratis, berkeadilan, dan tidak diskriminatif; (b) meningkatkan peran serta masyarakat dalam pendidikan; (c) pembangunan pendidikan diarahkan pada sector kebutuhan dasar, seperti sarana dan prasarana pendidikan dan pembelajaran, peningkatan kualitas guru, serta pembangunan lifeskill

\section{SARAN-SARAN}

1. Bagi kepala dinas pendidikan diharapkan : (a) menyelenggarakan pelatihan dan pendidikan bagi pengurus komite sekolah sehingga dapat menambah wawasan dan pengalaman komite sekolah; (b) pemerintah perlu mengintensifkan pengawasan terhadap kinerja dewan pendidikan, komite sekolah, dan satuan pendidikan yang dinaunginya agar dapat mencapai tujuan pendidikan nasional dengan baik.

2. Bagi komite sekolah diharapkan mampu menjadi mitra pemerintah dalam dunia pendidikan dengan menyusun perencaan pendidikan yang sesuai dengan kebutuhan, serta aktif dalam memberikan pertimbangan dan dukungan terhadap program yang telah dibuat, serta meningkatkan pengawasan terhadap keterlaksanaan program di setiap satuan pendidikan yang dinaunginya. Dalam pemilihan pengurus komite sekolah yang baru, agar memilih pengurus yang benarbenar siap dan memiliki waktu sehingga komite sekolah bisa menjalankan perannya sesuai dengan program dan rencana yang telah disepakati.

3. Bagi kepala sekolah hendaknya meningkatkan kerjasama dan komunikasi 
dengan komite sekolah, khususnya dalam meningkatkan mutu layanan pendidikan agar tujuan dalam program yang telah disusun dapat tercapai dengan baik.

4. Bagi masyarakat agar meningkatkan perhatian, kesadaran, dan tanggung jawabnya terhadap dunia pendidikan dengan terlibat aktif dalam setiap kegiatan dan program sekolah yang telah disusun bersama. Seluruh stakeholder pendidikan harus sadar bahwa peningkatan mutu layanan pendidikan tidak hanya membutuhkan sumbangan dana, tetapi juga saran dan kritikan.

\section{DAFTAR PUSTAKA}

Bungin, Burhan.2007. Metode Penelitian Kualitatif; Aktualisasi Metodelogi ke Arah Ragam Varian Kontemporer. Jakarta : PT. Raja Grafindo Persada.

Sartika, Ikke Dewi. 2002. Quality Service in Eduacation. Edisi Khusus untuk Kalangan Mahasiswa. Bandung: Kantor Yayasan Potensia.

Sujanto, Bedjo. 2007. Manajemen

Pendidikan Berbasis Sekolah;Model

Pengelolaan Sekolah di Era Otonomi

Daerah. Jakarta : CV. Sagung Seto.

Raharjo, Budi. 2003. Depdiknas. Manajemen

Berbasis Sekolah. Jakarta: Balai

Pustaka.

Riyanto.2007. Peran Komite Sekolah di SD Negeri Karanglo Unit Pendidikan Kecamatan Cilongok Kabupaten Banyumas. Jogjakrta.UNY.

Permendiknas No. 15 Tahun 2010 tentang Standar Pelayanan Minimum

Pendidikan Dasar. Jakarta : Lembaga Informasi Nasional.

Keputusan Menteri Pendidikan Nasional

Nomor. 044/U/2002. Kementerian
Pendidikan Nasional Republik Indonesia.

Undang-undang No. 20 Tahun 2003 tentang Sistem Pendidikan Nasional. Jakarta : Lembaga Informasi Nasional.

Undang-undang No. 25 Tahun 2002 tentang Peran serta Masyarakat dalam Pendidikan. Jakarta : Lembaga Informasi Nasional.

Permendiknas No.19 Tahun 2005 tentang Standar Nasional Pendidikan.

Permendiknas No. 15 Tahun 2010 tentang Standar Pelayanan Minimum Pendidikan Dasar. Jakarta : Lembaga Informasi Nasional. 